Article

\title{
Extraction Kinetics of As(V) by Aliquat-336 Using Asymmetric PVDF Hollow-Fiber Membrane Contactors
}

\author{
Said Bey ${ }^{1, *}$, Hassina Semghouni ${ }^{2}$, Alessandra Criscuoli ${ }^{2}$, Mohamed Benamor $^{1}$, \\ Enrico Drioli 2 (D) and Alberto Figoli ${ }^{2, * \text { (D) }}$ \\ 1 Laboratoire des Procédés Membranaires et des Techniques de Séparation et de Récupération, \\ Faculté de Technologie, Université de Bejaia, Béjaïa 06000, Algérie; mohamedbenamor@yahoo.fr \\ 2 Institute on Membrane Technology (ITM-CNR), Via P.Bucci 17/C, 87030 Rende (CS), Italy; \\ semghounihassina@gmail.com (H.S.); a.criscuoli@itm.cnr.it (A.C.); e.drioli@itm.cnr.it (E.D.) \\ * Correspondence: saidbey06@yahoo.com (S.B.); a.figoli@itm.cnr.it (A.F.); Tel.: +213-662-288-200 (S.B.)
}

Received: 23 June 2018; Accepted: 24 July 2018; Published: 2 August 2018

\begin{abstract}
This work focuses on the study of the mass transfer of arsenic $(\mathrm{V})$ through asymmetric polyvinylidene fluoride hollow-fiber membrane contactors using Aliquat-336 as an extractant. In the first part of this work, the fibers were prepared and characterized by SEM and by determining their thickness and porosity. From SEM pictures, an asymmetric structure was obtained that was characterized by an inner sponge-like structure and outer finger-like structure with a pore radius and porosity about $0.11 \mu \mathrm{m}$ and $80 \%$, respectively. In the second part, the prepared fibers were used as membrane contactors for the study of mass transfer of arsenic $(\mathrm{V})$, investigating the effect of several parameters such as $\mathrm{pH}$, temperature, and initial concentration of the feed. The overall mass transfer coefficient of $\mathrm{As}(\mathrm{V})$ was around $6 \times 10^{-6} \mathrm{~cm} / \mathrm{s}$.
\end{abstract}

Keywords: As(V); membrane contactor; Aliquat-336

\section{Introduction}

Arsenic, a highly toxic element, can be found in natural water system in its two main forms, organic and inorganic. Generally, inorganic arsenic has two different oxidation states in aqueous solution: trivalent and pentavalent [1]. It is introduced into the human body through drinking water and food, causing lung, liver, kidney, and skin cancer. Its consumption also leads to disturbance of cardiovascular and nervous system function, which eventually leads to death $[1,2]$. The presence of arsenic in nature is due to its abundance in the Earth's crust and as a result of pyro-metallurgical and hydrometallurgical activities. Moreover, arsenic was used for wood preservation, as anti-fungicide in agriculture, as additives for lead car batteries, and in semiconductor industries. A rich review on arsenic in metallurgy was reported by Nazari et al. [3].

Up to now, several techniques were developed for arsenic removal, such as precipitation, ion exchange, adsorption, membrane process, and solvent extraction [1,4-12]. In the literature, the most employed adsorbents for arsenic removal were reported in a critical review by Mohan et al. [10]. However, these systems present many drawbacks in terms of cost and regeneration of the activate materials. In the last two decades, liquid membranes gained an important interest for arsenic removal from aqueous solution. Perez et al. [9] studied As(V) transport through a supported liquid membrane impregnated with Cyanex-921. They reported that more than $94 \%$ of $\mathrm{As}(\mathrm{V})$ was transported in two hours. Hollow fiber-supported liquid membrane using Cynaex-923, tri-nbutyl phosphate (TBP), Cyanex-301, trioctyl amine (TOA), and Aliquat-336 as extractant was used in As(V) transport. In this study, Panchroen et al. [13] reported the transport of $\mathrm{As}(\mathrm{V})$ from produced water in the gas separation 
plant in the Gulf of Thailand with efficiency depending on the type of extractant. They reported that Aliquat-336 at 35\% (v/v) allows a high percentage of extraction of As(V). Güell et al. [14] focused their investigation on the transport of $\mathrm{As}(\mathrm{V})$ through a supported liquid membrane containing Aliquat-336 as a mobile carrier and compared its performance with that of an anion exchange membrane. They reported the effective transport of $\mathrm{As}(\mathrm{V})$ by the two systems. In our previous work [15], asymmetric hollow-fiber membrane contactors based on PVDF using Aliquat-336 in kerosene were employed. From the experimental tests, the extraction of $\mathrm{As}(\mathrm{V})$ was effective with an efficiency of $70 \%$. Recently, Srivastava et al. [16] investigated the extraction of $\mathrm{As}(\mathrm{V})$ by emulsion liquid membrane using Aliquat-336 and 2-ethyl hexanol. From the results, 2-ethyl hexanol is a better carrier for $\mathrm{As}(\mathrm{V})$ removal from aqueous solution at low $\mathrm{pH}$. In the literature, a review on the extraction of arsenic by liquid membrane was reported by Marino and Figoli [17]. Table 1 summarizes the most important research on Arsenic removal by liquid membranes.

Table 1. Removal of arsenic by liquid membrane systems.

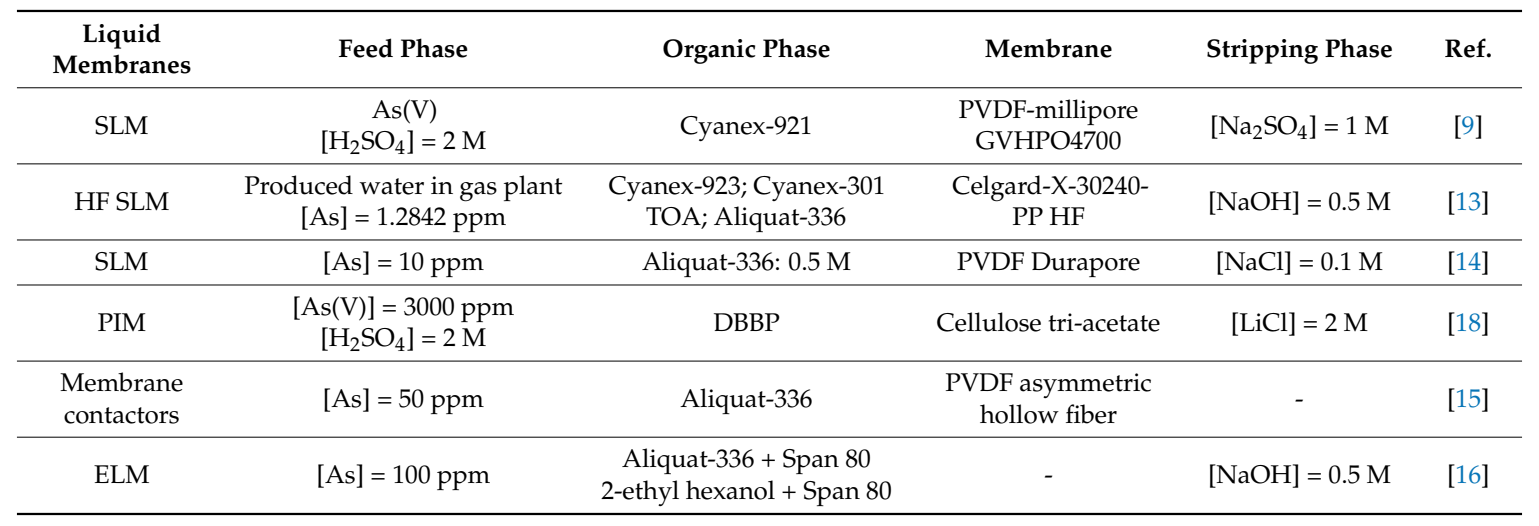

With respect to liquid membranes that suffer from the problem of organic loss and consequent reduced membrane stability, membrane contactors present a longer life-time during liquid-liquid extractions. For arsenic removal, Aliquat-336 has often been used in the organic phase in both types of membrane operations, as reported in Table 1. Therefore, considering the positive results obtained in our previous work with this extractant [15], a deeper analysis of the system in terms of overall mass transfer coefficient is presented in this paper. In particular, this work focuses on the extraction kinetics of $\mathrm{As}(\mathrm{V})$ by Aliquat-336 using hollow-fiber membrane contactors.

\section{Experimental}

\subsection{Chemicals}

Methyl trioctylammonium chloride (Aliquat-336) (Sigma-Aldrich, Darmstadt, Germany) was used as extractant. The diluent was analytical-grade kerosene (Sigma-Aldrich) used without further purification. PVDF Solef ${ }^{\circledR} 6012$ polymer powder was kindly provided by Solvay Specialty Polymer (Bollate, Italy) and used for the preparation of the hollow-fiber membranes.

\subsection{Preparation of PVDF Microporous Hollow-Fiber (HF) Membranes by Dry-Wet Spinning Process}

In the first part of the experimental study, hydrophobic PVDF hollow-fiber membranes have been produced by dry-wet spinning process. The polymeric solution was doped with water and polyvinyl pyrrolidone, PVP (k17), a modifier (BASF, Ludwigshafen, Germany), and dimethyl formamide (DMF) was used as solvent. Bore liquid consisted of DMF and water at 25/75 $(v / v)$. They were heated and pumped through the inner tube of the spinneret with the flow rate of $20 \mathrm{~mL} / \mathrm{min}$. The experimental set up of hollow-fiber membranes preparation is shown in our previous work [15].The structural and permeation-related parameters of the prepared hydrophobic hollow-fiber membranes were 
characterized by means of dimensional and performance factors. Among dimensional parameters, outside $\left(\mathrm{d}_{\mathrm{o}}\right)$ and inside diameters $\left(\mathrm{d}_{\mathrm{i}}\right)$ and the thickness $(\delta)$ of the fibers were measured. Pore size, porosity, and pore radius also were measured. Moreover, the porous structures of the membranes were documented by the scanning electron microscopy (SEM) pictures.

\subsection{Non-Dispersed Solvent Extraction of As(V) by Aliquat-336}

The non-dispersed solvent extraction experiments were carried out using a lab-made module based on PVDF asymmetric hollow fibers prepared by immersion-precipitation. The organic phases were prepared by dissolving Aliquat-336 in kerosene modified by $4 \%$ of octanol to avoid any phase segregation. The feeding solution of arsenic was prepared by dissolving a certain quantity of $\mathrm{NaHAsO}_{4}$ in bi-distilled water. The aqueous feed phase flowed in the lumen side and the organic in the shell side. In this case, since the organic phase wets spontaneously the membrane, a positive static pressure on the aqueous feed phase was applied, to prevent the organic from dispersion into the aqueous feed phase to form an emulsion. The experiments were carried in recirculating mode and samples of $1 \mathrm{~mL}$ were taken from the reservoir. The volumes of organic and aqueous phases were $175 \mathrm{~mL}$ and $300 \mathrm{~mL}$ respectively. Each experiment was repeated at least two times. The maximum error was $\pm 2 \%$. The concentration of arsenic ions was determined by inductivity coupled plasma spectroscopy. Figure 1 shows the scheme of the hollow-fiber membrane contactors set up.

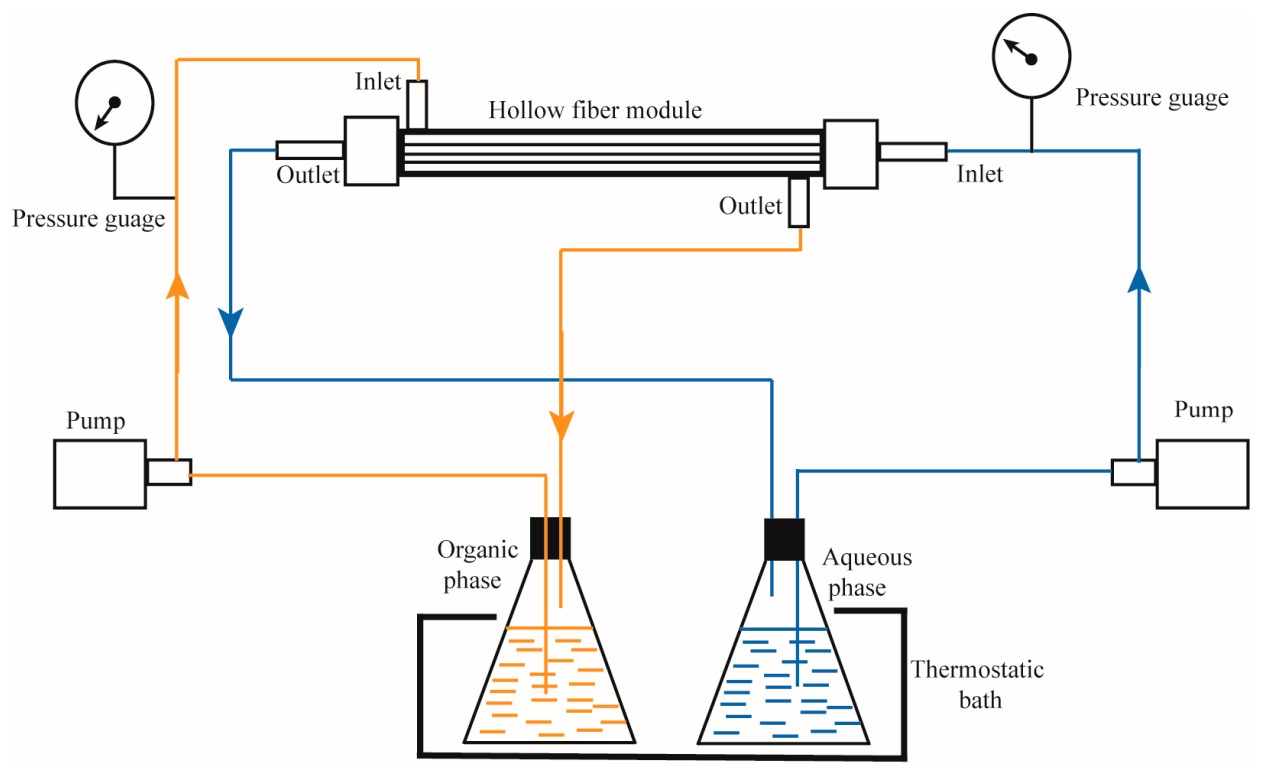

Figure 1. Hollow-fiber membrane contactors set up.

The overall mass transfer coefficients $K$ was calculated from the following equation, obtained from a mass balance on the system $[19,20]$.

$$
K=-\frac{d \cdot v}{4 \cdot L} \frac{1}{\left(1+\left(\frac{Q_{\text {in }}}{H \cdot Q_{\text {out }}}\right)\right)} \cdot \ln \left[1+\frac{V_{\text {in }} \cdot\left(\left(1 / Q_{\text {in }}\right)+\left(1 / Q_{\text {out }}\right)\right)}{1+\left(V_{\text {in }} / H \cdot V_{\text {out }}\right)} \cdot \frac{\ln \left(\Delta C / \Delta C_{0}\right)}{t}\right]
$$

where

$$
\ln \frac{\Delta C}{\Delta C_{0}}=\ln \frac{C_{\text {in }}\left(1+\left(V_{\text {in }} / H \cdot V_{\text {out }}\right)\right)-C_{\text {in }}^{0}\left(\left(V_{\text {in }} / H \cdot V_{\text {out }}\right)-\left(C_{\text {out }}^{0} / H\right)\right)}{C_{\text {in }}^{0}-\left(C_{\text {out }}^{0} / H\right)}
$$

where

$d$ : inside hollow fiber diameter; 
v: aqueous flow velocity;

$L$ : length of the fiber;

$H$ : partition coefficient;

$Q_{i n}$ and $Q_{o u t}$ are the aqueous and the organic flow rates, respectively;

$V_{\text {in }}$ and $V_{\text {out }}$ are the aqueous and the organic reservoir volumes, respectively;

$C_{i n}, C_{i n}^{0}$ and $C_{o u t}^{o}$ are the aqueous feed concentration at time $t$, the initial aqueous feed concentration and initial organic concentration, respectively.

In the extraction of $\mathrm{As}(\mathrm{V})$, the form of the species in water is important, especially when an ion exchange process was used. In our case, a basic extractant, Aliquat-336 diluted in kerosene, was used. The basic equilibrium and effect of the $\mathrm{pH}$, in the range of 0.87 to 12.5 , were studied. The reaction involved in the extraction is an ion exchange between Aliquat-336 and the oxyanions of $\mathrm{As}(\mathrm{V})$, depending on $\mathrm{pH}$ of the aqueous solution and the forms of the oxyanions. It seems that the divalent and monovalent oxyanions of $\mathrm{As}(\mathrm{V})$ present in the $\mathrm{pH}$-range 6.98 to 8.2 are favorable for extraction by Aliquat-336 according to the equations below.

$$
\begin{gathered}
\overline{\left(\mathrm{R}_{3} \mathrm{NH}^{+}, \mathrm{Cl}^{-}\right)}+\mathrm{H}_{2} \mathrm{SO}_{4}^{-} \Leftrightarrow \overline{\left(\mathrm{R}_{3} \mathrm{NH}^{+}, \mathrm{H}_{2} \mathrm{SO}_{4}^{-}\right)}+\mathrm{Cl}^{-} \\
\overline{2\left(\mathrm{R}_{3} \mathrm{NH}^{+}, \mathrm{Cl}^{-}\right)}+\mathrm{H}_{2} \mathrm{AsO}_{4}^{2-} \Leftrightarrow \overline{\left(\mathrm{R}_{3} \mathrm{NH}\right)_{2} \mathrm{HAsO}_{4}}+2 \mathrm{Cl}^{-}
\end{gathered}
$$

\section{Results and Discussion}

\subsection{SEM Analysis}

SEM pictures show an asymmetric structure characterized by a large inner sponge structure and a thin finger-like structure at the outer surface. The asymmetry of the fiber can be appreciated by looking inner and outer surfaces of the hollow fibers that are porous and smooth, respectively (Figure 2).
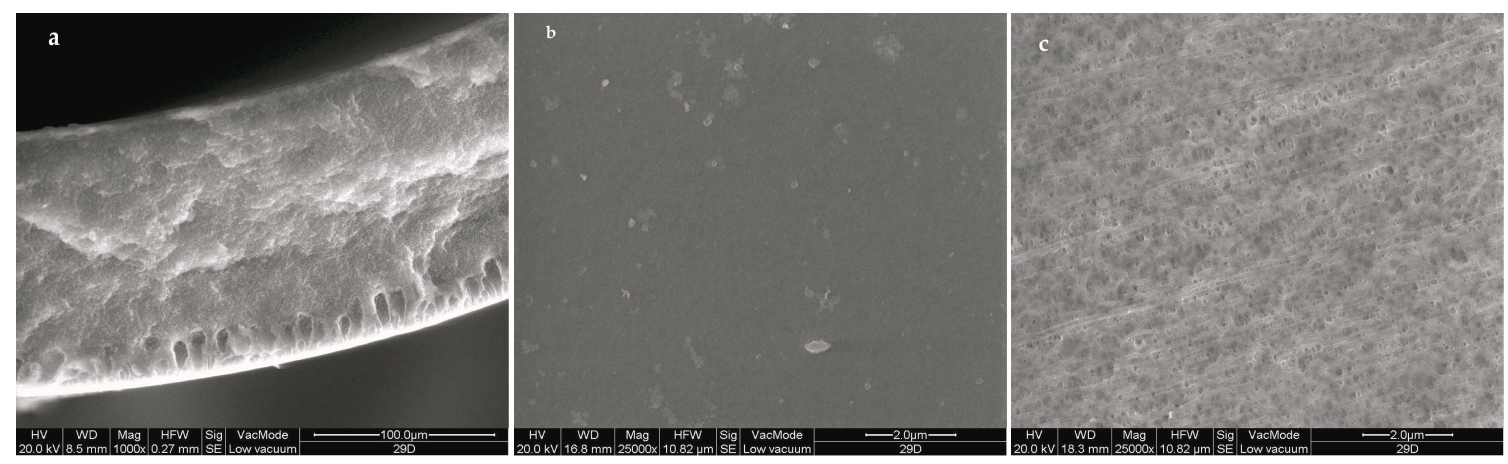

Figure 2. Scanning electron microscopy (SEM) pictures of the cross-section (a), the outer (b), and inner (c) surfaces of hollow fibers.

Table 2 summarizes the properties of the modules used in this study.

Table 2. Properties of the hollow-fiber membrane contactors module.

\begin{tabular}{cc}
\hline Properties & Description \\
\hline Material & PVDF \\
Hollow fiber inner diameter $(\mathrm{mm})$ & 1.35 \\
Pore size $(\mu \mathrm{m})$ & 0.11 \\
Number of fibers & 3 \\
Porosity $(\%)$ & 80 \\
Surface $\left(\mathrm{cm}^{2}\right)$ & 22.9 \\
Module diameter $(\mathrm{cm})$ & 1 \\
Module length $(\mathrm{cm})$ & 18 \\
\hline
\end{tabular}




\subsection{Solvent Extraction Studies of As(V) by Means of Hollow-Fiber Membrane Contactors}

The basic equilibrium and mass transfer experiments produced the following results. Figure 3 shows the extraction of $\mathrm{As}(\mathrm{V})$ into $30 \%$ of Aliquat-336, as function of the $\mathrm{pH}$. The reaction involved in the extraction is an ion exchange type (Equations (3) and (4)). $\mathrm{Cl}^{-}$ions in Aliquat-336 are replaced by the oxyanions of $\mathrm{As}(\mathrm{V})$. Since the predominance of monovalent and divalent oxyanions of $\mathrm{As}(\mathrm{V})$ is for $\mathrm{pH}$ values from 6.98 to 8.2 , the high percentage of extraction is obtained in this $\mathrm{pH}$ range, reaching $70 \%$. By decreasing the $\mathrm{pH}$ to 4.5 the partition coefficient decreases, due probably to the formation of neutral species which cannot be extracted by Aliquat-336. At very low $\mathrm{pH}$ (close to zero) the neutral species are predominant and the extraction is very low. Furthermore, in basic medium at $\mathrm{pH}=12.5$ no extraction of arsenate was observed. Consequently, trivalent oxyanions of As(V) cannot be extracted by Aliquat-336. Accordingly, the rest of experiments were carried out with $30 \%$ of Aliquat-336 diluted in kerosene and initial aqueous $\mathrm{pH}$ of 6.98 .

In the hollow fiber experiments, the concentration of $\mathrm{As}(\mathrm{V})$ varies semi-logarithmically with time, as shown in Figure 4. In particular, the logarithm of the concentration difference is linear in time at the beginning of the experiment. This means that the data are consistent with Equation (1) and (2) at high metal concentration. Consequently, at short experiment time, the overall mass transfer coefficient from the initial slope of these data can be calculated. This overall mass transfer coefficient shows the behaviour of As(V) extraction in this system. For example, as reported in Table 3, it varies significantly with the initial concentration and $\mathrm{pH}$ of feed solution but weakly with temperature. In particular, the overall mass transfer coefficient increases by increasing the initial concentration of As $(V)$, reaching the value of $7 \times 10^{-6} \mathrm{~cm} / \mathrm{s}$ at $100 \mathrm{ppm}$. The result obtained at the high temperature of $50{ }^{\circ} \mathrm{C}$ could be explained by the presence of PVP in hollow fiber, which reduces the contact area between the two phases, or by the exothermic reaction of $\mathrm{As}(\mathrm{V})$ with the extractant.

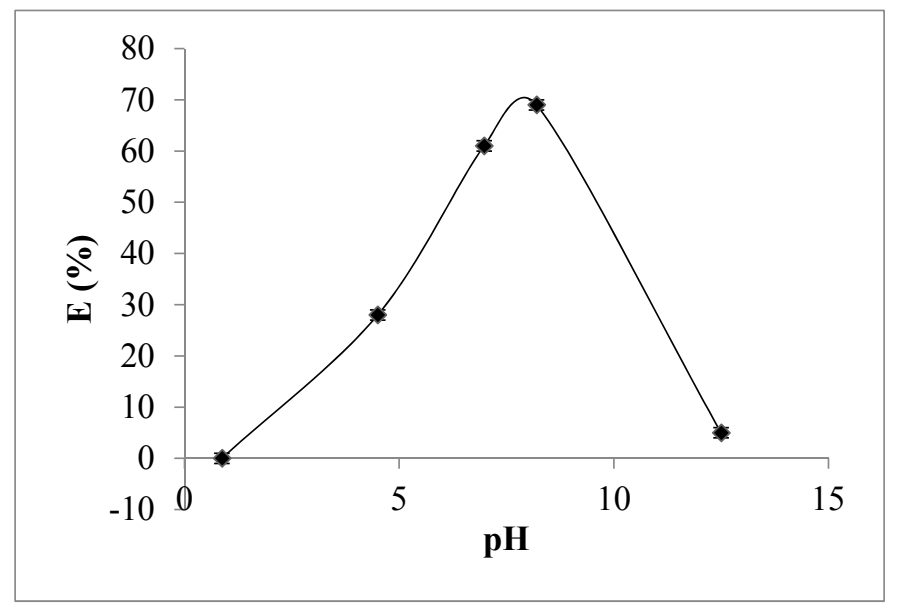

Figure 3. Equilibrium extraction of $\mathrm{As}(\mathrm{V})$ by Aliquat-336. Aqueous phase: $[\mathrm{As}(\mathrm{V})]=60 \mathrm{ppm}$, flow-rate: $0.47 \mathrm{~mL} / \mathrm{s}$. Organic phase: [Aliquat-336] $=30 \%(v / v)+$ Kerosene $+4 \%(v / v)$ octanol; flow-rate: $1.4 \mathrm{~mL} / \mathrm{s}$; Membrane: PVDF hollow fiber, $\mathrm{T}=25^{\circ} \mathrm{C} . \Delta \mathrm{P}=0.3$ bar. 


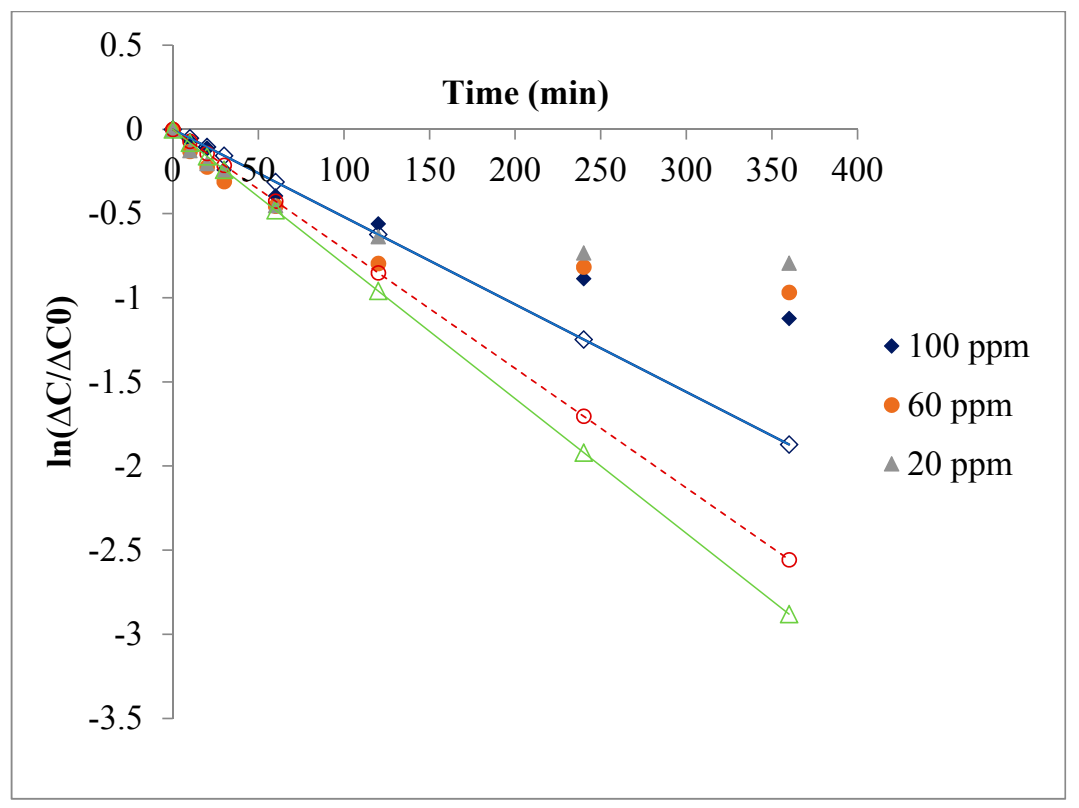

Figure 4. As $(\mathrm{V})$ concentration vs time. Aqueous phase: $\mathrm{pH}=6.98$; Flow-rate: $0.47 \mathrm{~mL} / \mathrm{s}$. Organic phase: [Aliquat-336] $=30 \%(v / v)+$ Kerosene $+4 \%(v / v)$ octanol; flow-rate: $1.4 \mathrm{~mL} / \mathrm{s}$; Membrane: PVDF hollow fiber, $\mathrm{T}=25^{\circ} \mathrm{C} . \Delta \mathrm{P}=0.3$ bar.

Table 3. Overall mass transfer coefficients of As(V).

\begin{tabular}{ccc}
\hline Parameters & & $\boldsymbol{K} \times \mathbf{1 0}^{\mathbf{6}} \mathbf{( \mathbf { c m } / \mathbf { s } )}$ \\
\hline & 12.5 & 0 \\
$\mathrm{pH}$ & 8.2 & $7.54 \% \pm 2 \%$ \\
& 6.98 & $6.05 \% \pm 2 \%$ \\
& 4.5 & $2.11 \% \pm 1 \%$ \\
\hline Initial As(V) concentration & 100 & $7.04 \% \pm 3 \%$ \\
$(\mathrm{ppm})$ & 60 & $6.05 \% \pm 2 \%$ \\
& 20 & $4.96 \% \pm 1.5 \%$ \\
\hline \multirow{2}{*}{ Temperature $\left({ }^{\circ} \mathrm{C}\right)$} & 25 & $6.05 \% \pm 2 \%$ \\
& 40 & $6.45 \% \pm 2.5 \%$ \\
& 50 & $3.45 \% \pm 1 \%$ \\
\hline
\end{tabular}

\section{Conclusions}

In this study, asymmetric hollow-fiber membranes were prepared by dry wet phase inversion and applied to extraction of $\mathrm{As}(\mathrm{V})$ by Aliquat-336 in hollow-fiber membrane contactors system under several conditions. Arsenic was extracted in its two mainly forms species such as monovalent and divalent by Aliquat-336. However, the trivalent forms in basic medium were not extracted. No effect of temperature on the kinetic extraction of $\mathrm{As}(\mathrm{V})$ was observed. The kinetic extraction was, on the contrary, affected by the initial feed concentration and $\mathrm{pH}$.

The mass transfer of $\mathrm{As}(\mathrm{V})$ through asymmetric PVDF hollow fibers was around $6 \times 10^{-6} \mathrm{~cm} / \mathrm{s}$, comparable to other metal ions-extractant/membrane contactors reported in the literature.

Author Contributions: The contribution of several authors are as following: Conceptualization, writing original draft, software and formal analysis, S.B.; Data curation and investigation, H.S.; Writing and correcting the original draft, A.F. and A.C.; Supervising, B.M. and E.D.

Funding: This research received no external funding.

Conflicts of Interest: We wish to confirm that there are no known conflicts of interest associated with this publication and there has been no significant financial support for this work that could have influenced its 
outcome. We confirm that the manuscript has been read and approved by all named authors and that there are no other persons who satisfied the criteria for authorship but are not listed. We further confirm that the order of authors listed in the manuscript has been approved by all of us. We confirm that we have given due consideration to the protection of intellectual property associated with this work and that there are no impediments to publication, including the timing of publication, with respect to intellectual property. In so doing we confirm that we have followed the regulations of our institutions concerning intellectual property. We understand that the Corresponding Author is the sole contact for the Editorial process (including Editorial Manager and direct communications with the office). He is responsible for communicating with the other authors about progress, submissions of revisions and final approval of proofs. We confirm that we have provided a current, correct email address which is accessible by the Corresponding Author and which has been configured to accept email from: saidbey06@yahoo.com, a.figoli@itm.cnr.it.

\section{References}

1. Jeon, C.S.; Kitae, B.; Park, J.K.; Oh, Y.K.; Lee, S.D. Adsorption characteristics of As(V) on iron-coated zeolite. J. Hazard. Mater. 2009, 163, 804-808. [CrossRef] [PubMed]

2. Qu, D.; Wang, J.; Hou, D.; Luan, Z.; Fan, B.; Zhao, C. Experimental study of arsenic removal by direct contact membrane distillation. J. Hazard. Mater. 2009, 163, 874-879. [CrossRef] [PubMed]

3. Nazari, A.M.; Radzinski, R.; Ghahreman, A. Review of arsenic metallurgy: Treatment of arsenical minerals and the immobilization of arsenic. Hydrometallurgy 2017, 174, 258-281. [CrossRef]

4. Katsoyiannis, I.A.; Zouboulis, A.I. Removal of arsenic from contaminated water sources by sorption onto iron-oxide-coated polymeric materials. Water Res. 2002, 36, 5141-5155. [CrossRef]

5. Chuang, C.L.; Fan, M.; Xu, M.; Brown, R.C.; Sung, S.; Saha, B.; Huang, C.P. Adsorption of arsenic(V) by activated carbon prepared from oat hulls. Chemosphere 2005, 61, 478-483. [CrossRef] [PubMed]

6. Guo, H.; Stüben, D.; Berner, Z. Arsenic removal from water using natural iron mineral-quartz sand columns. Sci. Total Environ. 2007, 377, 142-151. [CrossRef] [PubMed]

7. Lohokare, H.R.; Muthu, M.R.; Agarwal, G.P.; Kharul, U.K. Effective arsenic removal using polyacrylonitrile-based ultrafiltration (UF) membrane. J. Membr. Sci. 2008, 320, 159-166. [CrossRef]

8. Lv, J.; Wang, K.Y.; Chung, T.S. Investigation of amphoteric polybenzimidazole (PBI) nanofiltration hollow fiber membrane for both cation and anions removal. J. Membr. Sci. 2008, 310, 557-566. [CrossRef]

9. Perez, M.E.M.; Reyes-Aguilera, J.A.; Saucedo, T.I.; Gonzalez, M.P.; Navarro, R.; Avila-Rodriguez, M. Study of $\mathrm{As}(\mathrm{V})$ transfer through a supported liquid membrane impregnated with trioctylphosphine oxide (Cyanex 921). J. Membr. Sci. 2007, 302, 119-126. [CrossRef]

10. Mohan, D.; Pittman, C.U., Jr. Arsenic removal from water/wastewater using adsorbents-A critical review. J. Hazard. Mater. 2007, 142, 1-53. [CrossRef] [PubMed]

11. Tresintsi, S.; Simeonidis, K.; Katsikini, M.; Palourac, E.C.; Bantsis, G.; Mitrakas, M. A novel approach for arsenic adsorbents regeneration using MgO. J. Hazard. Mater. 2014, 265, 217-225. [CrossRef] [PubMed]

12. Xu, W.; Wang, J.; Wang, L.; Sheng, G.; Liu, J.; Yu, H.; Huang, X.J. Enhanced arsenic removal from water by hierarchically porous $\mathrm{CeO} 2-\mathrm{ZrO} 2$ nanospheres: Role of surface- and structure-dependent properties. J. Hazard. Mater. 2013, 260, 498-507. [CrossRef] [PubMed]

13. Pancharoena, U.; Poonkuma, W.; Lothongkum, A.W. Treatment of arsenic ions from produced water through hollow fiber supported liquid membrane. J. Alloy. Compd. 2009, 482, 328-334. [CrossRef]

14. Güella, R.; Fontàs, C.; Anticó, E.; Salvadó, V.; Crespo, J.G.; Velizarov, S. Transport and separation of arsenate and arsenite from aqueous media by supported liquid and anion-exchange membranes. Sep. Purif. Technol. 2011, 80, 428-434. [CrossRef]

15. Bey, S.; Criscuoli, A.; Figoli, A.; Leopold, A.; Simone, S.; Benamor, M.; Drioli, E. Removal of As(V) by PVDF hollow fibers membrane contactors using Aliquat-336 as extractant. Desalination 2010, 264, 193-200. [CrossRef]

16. Srivastava, A.; Bhagat, A.; Sharma, U.; Dohare, R.K.; Singh, K.; Upadhyaya, S. Comparative study of arsenic(V) removal from aqueous solution usingAliquat-336 and 2-ethyl hexanol through emulsion liquid membrane. J. Water Process Eng. 2017, 16, 64-68. [CrossRef]

17. Marino, T.; Figoli, A. Arsenic Removal by Liquid Membranes. Membranes 2015, 5, 150-167. [CrossRef] [PubMed] 
18. De Lourdes, B.M.; de Rodríguez, S.M.E.; de MT, J.R.; Silva, O.; Muñoz, M.; de Gyves, J. Arsenic(V) removal with polymer inclusion membranes from sulfuric acid media using DBBP as carrier. Environ. Sci. Technol. 2004, 38, 886-891.

19. Elia, N.A.D.; Dahuron, L.; Cussler, E.L. Liquid-liquid extractions with microporous hollow fibers. J. Membr. Sci. 1986, 29, 309-319. [CrossRef]

20. Yang, C.; Cussler, E.L. Reaction dependent extraction of copper and nickel using hollow fibers. J. Membr. Sci. 2000, 166, 229-238. [CrossRef]

(c)

(C) 2018 by the authors. Licensee MDPI, Basel, Switzerland. This article is an open access article distributed under the terms and conditions of the Creative Commons Attribution (CC BY) license (http://creativecommons.org/licenses/by/4.0/). 